\title{
PROLEGOMENA FOR A PRE-MODERN GEOPHILOSOPHY
}

\author{
DOI: http://dx.doi.org/10.18509/GBP.2020.100
}

UDC: 1.073:91(497.2)

\section{Goran Mutabdžija}

Faculty of Philosophy, University of East Sarajevo, Bosnia and Herzegovina

\begin{abstract}
This paper is an attempt to creation of framework for reading geographical thinking during premodern times. It is two and half -millennium period of geographical imagination that began with Anaximander (VI BC), representative of the Milesian school and ended with the death of two of the first scientific geographers, von Humboldt and von Ritter (1859). Through the analyse the subjects of the study of geography [17, 20, 6, 12] we can understand the complexity of the contemporary development of geographical thinking and the dispersion of different philosophical directions over the 20th century. They crucially influenced the emergence of different geographical conceptions within the geography of modern and postmodern geographies, which cannot be understood without this development during premodern. This leads us to confirm the thesis that scientific thought, even geographic, has never been completely separated from philosophical thought, and that it is always within one frame of ideas, which in its conception is philosophical. The philosophical foundations of geographical thinking, based on the notions of space, ethics, and environment are examined through the different works [7, 4, 15]. It brought us closer to the notion of geophilosophy, which best reflects this connection between philosophical conceptions and geography. Through this relevant texts we have considered the aspirations of philosophers to acquire new horizons of knowledge i.e. "Geist der Schwere" [13], which were the pretext for the on the essential concepts of geophilosophy (territorialisation, reterritorialization, miles) [3] and on geotrauma [14]. Based on contemporary interpretations of the term geophilosophy $[8,10,18$, 19], the connection between "way of thinking, environment and Earth" is understood. At finally, suggested that this long period in the development of geography be presented through the chrestomathy of the works of the most significant representatives of its epoch.
\end{abstract}

Key words: geographical thinking, pre-modern, philosophy, geophilosophy, horizons of knowledge.

\section{INTRODUCTION}

The main aim of this paper is to create the optimal way to meet the challenges and solutions that geography has provided us for two and a half millennia. These challenges have been changing during this period, especially when viewed from today's perspective in which geography ${ }^{13}$ studies the various relationships between population and nature. In doing so, the emphasis is on exploring place, space and environment with the obligatory question: where, what, how and why. In addition to the geographical distribution and characteristics of the population and objects, understanding the processes, systems and

\footnotetext{
${ }^{13}$ Based on: Geography Working Group's Interim Report, UK Department of Education and Science, 1990.
} 
relationships that affect their meanings is also important. This also applies to looking at specific patterns of behaviour that arise by creating them physically where they live and work. At the same time, the study of the environment has both a natural and a social dimension, with human activity affecting these resources as well as their interconnectedness with different consequences (social, economic, political and cultural). From this broad definition of the subject itself, there is a clear focus on how to shape and change social forms, but also to accelerate the transformation of the natural environment. Consequently, human-influenced, "primordial" forms emerge from the primordial natural environment, creating the environment and making these "sedimentary layers of socialization" with one another, as a consequence, create a complex natural and social landscape. Geography also examines ways in which nature influences society, from how raw materials and social forces influence the progress of human society and its culture. Complex interrelationships emerge from the relations of society and nature, because what used to be a causal relationship, mostly in one direction, becomes an equally causal connection in the opposite direction. This means that human activity continuously creates a new context in which nature becomes a social construction, in terms of human social and economic forces, and which reshapes space through the intervention of ideas and the application of different discourses. That is reason why understanding this system of relationships requires "geographers sophisticated knowledge of the natural and social sciences, as well as the ability to find ways to combine the two elements: on the one hand it is knowledge of methods, and on the other, it is a thrill of insight into both aspects knowledge" [17]. In this way, the synthesis core of geography becomes the study of the interrelationships between nature and society, with differences within the natural environment becoming a source of cultural differences, and consequently, leading to a change in the methodological framework of geography. Simplified, essence of the subject of geography lies in the processes of development and mutual relations between man (society) and nature, from which the universal and eternal questions of science and philosophy emerge. Real geographical space is like open book, "easy to read but difficult to understand", because in order to understand it one must enter deeply into the relations and processes on the relations between nature and society. Therefore, geography as an area of science, which distinguishes specific spatial systems "linked by specific connections, which unites them into complex regions, both differentiated by components and integrated by natural and social processes"[6].

Since this process took place in a straightforward and successive manner during the premodern one, it is only an introduction to the contemporary development of geographical thinking, which stems from the dispersion of the various philosophical directions that took place during $20^{\text {th }}$ century. Therefore, the study of different directions within the geography of modernity, whether it be positivism (anthropogeography, regional geography, cultural geography and quantitative geography), behaviourism (functionalism and pragmatism), humanistic approaches (existentialism, phenomenology and idealism) or structuralism (feminism and Marxism), implies an understanding of philosophical directions of the same name. The same is true of postmodern geography (critical geography, postmodern geography and post structuralism), which implies knowledge not only of their semantics, but also of a broader cognitive framework and interconnectedness. Therefore, it is necessary to understand the whole of this process from the emergence of geographical thinking during premodern times, during which this process took place in a straight line and in succession. Such a wide time span of study implies an adequate name for such a synthesis (historical-geographical development, 
geographical thinking, philosophy of geography, or geophilosophy). Given the subject matter and its structure, it is clear that this should not be a kind of catalogue of brief overviews of particular geographical styles that originated in philosophical lines of the same name. Nor should it be a Hegelian view of the historical development of the philosophy of geography, whereby that work would also be philosophy. More modestly, this synthesis should point to clear links between geographical thinking and its origins in philosophy during the historical development of premodernity, presented in a systematic manner based on dialectical thinking. For, it is a well-known fact that scientific thought, even geographic, has never been completely separated from philosophical thought, and that it is always within one frame of ideas, which in its conception is philosophical. Therefore, the term geophilosophy having multiple meaning was chosen.

\section{WHAT IS GEOPHILOSOPHY?}

To put it simply, the term geophilosophy refers to the philosophical aspects of geographic (geological) processes. The term itself refers to the German writer F. Nietzsche, who in many of his books ${ }^{14}$ strongly emphasized the desire (philosopher) to conquer new horizons. The titles of Nietzsche's quotes indicate that philosophers become " aeronauts of the intellect ", "brave birds that fly far, very far", and that they are on the march "across the sea", overwhelmed by a "powerful desire". A parallel between Dante's Odyssey and Nietzsche's "aeronauts of the intellect" in such a way that they both rely solely on themselves and their direction is determined by the same "craving for cognition" [18].

We aeronauts of the intellect.-All those daring birds that soar far and ever farther into space, will somewhere or other be certain to find themselves unable to continue their flight, and they will perch on a mast or some narrow ledge - and will be grateful even for this miserable accommodation! But who could conclude from this that there was not an endless free space stretching far in front of them, and that they had flown as far as they possibly could? In the end, however, all our great teachers and predecessors have come to a standstill, and it is by no means in the noblest or most graceful attitude that their weariness has brought them to a pause: the same thing will happen to you and me! but what does this matter to either of us? Other birds will fly farther! Our minds and hopes vie with them far out and on high; they rise far above our heads and our failures, and from this height they look far into the distant horizon and see hundreds of birds much more powerful than we are, striving whither we ourselves have also striven, and where all is sea, sea, and nothing but sea! And where, then, are we aiming at? Do we wish to cross the sea? whither does this over-powering passion urge us, this passion which we value more highly than any other delight? Why do we fly precisely in this direction, where all the suns of humanity have hitherto set? Is it possible that people may one day say of us that we also steered westward, hoping to reach India- but that it was our fate to be wrecked on the infinite? Or, my brethren? or-?" [13].

Like Copernicus, Columbus revolutionized space, declaring "the victory of infinity over the material limitations of what is present and tangible" (...) driven by "an adventurous longing for immense distances and for all that is unknown and dangerous" (...), as well as untamed by the necessity to master the vast expanses [18]. Nevertheless, geophilosophy has a far more complex meaning in the domain of postmodern philosophy. The most complete elaboration of the philosophical meaning of this term geophilosophy

\footnotetext{
${ }^{14}$ Down of Day, The Joyous Science, Fragmentos póstumos (1882 -1885).
} 
explores the intricate relationships between thought, territory, and the Earth itself, and its key concepts are: miles, territorialisation, reterritorialization, geo-trauma, and thought. Under the term territorialisation, it refers to "the expressive process of marking conceptual, social and physical architectures that provide space for cohabitation, together with the associated environment (terrestrial) and milieu" [3]. On the contrary, reterritorialization refers to the dissolution or abandonment of existing territories in order to form new assemblies through the constant change of "thinking, movement, articulation, framing and other modes of coexistence". Where territorialisation is present, there are tendencies towards order, boundary, codification, structure, stability, habits and constraints, while reterritorialization is used by "forces of chaos, disorder, variation, release, mobility and infinity". Geophilosophy thus re-examines the nature of thought as "a geological process that is in constant contact with the Earth itself," "as more of a multitude movement that pertains to territories rather than to cognitive abilities limited to objects already formed." In one of their recent works they specifically emphasize the existence of specific geo-traumas resulting from "looting, sedimentation, groundlessness, and stratification of the Earth's ecological states to maintain unregulated economic growth and social control of geographic spaces" which provide the future of petro-capitalism [3]. Interpreting these views, Negerestani sees oil and narcotics (drugs) as the lubricants of post-industrial world capitalism. Within it, as the first geo-trauma, recognizes the need for the continual conquest, commodification ${ }^{15}$ and appropriation of ecological systems by petro-capitalist regimes, while the second trauma involves the suppression of creative forms of thought and collective social action, which could prevent ecological catastrophe by creating "new ecologies", based on locality and activism. This form of geo-trauma effectively captures individuals and societies in the present that seem both unbearable and insurmountable, so that we "continue to suffer shameful compromises" instead of exploring creative alternatives for a future life path. [14]

The notion of geophilosophy can be summed up in the idea that philosophy, or science in general, needs a creative milieu to develop in which events can be localized in time and space but not explained by the natural characteristics of that specific environment. The identification of that creative milieu, in the history of science or the geography of ideas, is not a single theme, but a central issue of geophilosophy. For this reason, he recognizes two associations regarding the term geophilosophy (ecological and geopolitical), the first as "more or less esoteric" which has to do with ecological thinking in terms of "deep ecology" [19]. The second can be considered a philosophical version "geopolitics" used in the critique of implied political territoriality ${ }^{16}$. It could be emphasizing the adaptation of geographic notions of closeness, unpredictability, interdisciplinary, including the linearity of historical ideas, or notes that recently a number of scholars have explored the "convergence of speculative fiction with geophilosophy as a way of addressing social and environmental traumas" associated with petro capitalism, climate change and the bio politics of the Anthropocene epoch ${ }^{17}[10]$.

\footnotetext{
${ }^{15}$ See the geographical aspect of this process in: Mutabdzija, 2018.

${ }^{16}$ Günzel thinks of Lyotard (1988) who did the work of M. Heidegger described as a philosophy of "blood and soil".

${ }^{17}$ The International Union of Geological Sciences (IUGS) notes that the Holocene, which has lasted for the past 12,000 years, has ended and that the "epoch of man" (the Anthropocene) has occurred. There is a dilemma about the beginning of the Anthropocene, for one it was 1950. (nuclear tests), and for others the beginning of the industrial revolution.
} 
Due to the complexity of postmodern interpretations of the term geophilosophy, we will dwell on the first meaning, because this term, outside the narrow framework (geography or philosophy), associates with the whole, that is, multiple aspects concerning the relationship between man and space. Given the territoriality of the geography discussed by Kant [4] and the meanings of geographical elements and their interpretability in the field of culture, as Gadamer [9] it is obvious that they go beyond purely geographical dates and acquire symbolic ones, historical and philosophical dimensions.

"Geophilosophy is seen as an attempt to explore the complex meaning of human habitation on Earth. Contrary to the uniformity of the global world, which erases differences and particularities, triggering everywhere irreversible processes of eradication and loss of cultural identity, geophilosophy is primarily aimed at capturing and protecting the elusive spiritual, cultural, historical and spatial physiognomy of communities and places, with an awareness of that the meaning of our "earthly" existence can only be found if it comes from the plurality of human communities that, each time in a unique way, inhabit a time and place, giving them an absolutely unique and inimitable seal. They reside in geo-historical and geo-symbolic spaces that are never closed to themselves but are always open to the arrival of the other, the only one who can guarantee them not only mere survival but life itself in the changing course of history, fusing memory and change [18].

\section{THE PHILOSOPHICAL FOUNDATIONS OF GEOGRAPHICAL THINKING}

To clarify the essence of these processes that arise in the interaction of nature and society, it is not enough just the level of descriptiveness of these processes or the consequences of their action, which we see on the earth's surface and recognize them in spatial terms as terms: space, region, environment, landscape, place. It is necessary to understand their transcendental meaning (according to Kant, transcendental represents "knowledge that is not occupied with objects at all, but with our way of knowing objects"), i.e. discover the levels of that knowledge. From this point on, geography ceases and philosophy begins, epistemology that deals with the theory of cognition. In an effort to point out the importance and closeness of certain philosophical and geographical ideas, the title of Part I should be "Geographic Thinking during Premodernity", which frames more than two millennia of development of geographical thinking, from Anaximander to Kant. The structure of this section, which has a chronological-evolutionary dimension, is well described by the name of one of the most important journals in this field ${ }^{18}$. It is necessary to make some terminological clarification here, not only because of the terms that define this title, but because of the methodological framework of the research in this manuscript. This geographical synthesis should imply a certain degree of understanding of philosophical concepts, so that the subject matter of the work will emerge from a purely geographical field, with the ambition to understand the broader philosophical framework in which different geographical ideas have evolved throughout history. The term ethics is derived from the Greek words ethicos and ethos, which have the meaning of habit, custom. It is an area of philosophy that encompasses systematizing, defending and recommending the concepts of right and wrong behaviour, which can be interpreted as the science of morality. The sublimation of the concepts of morality and reasoning also

\footnotetext{
${ }^{18}$ Ethics, Space and Environment: A Journal of Philosophy and Geography
} 
leads us into the world of ontology, in which Plato paved the way to "the cause and source of every being and truth, every reality and goodness." It is for him a god, a father, an eternal being and a creator (demiurge) who created the cosmos and the whole visible world, man and all living beings. This character of cosmogonic plays from the ancient world will subsequently be transferred to early Christian teaching and become part of dogma, e.g. ideas about eternal life or the immortality of the soul. Vasily the Great will deviate from the Hellenic teaching of creation on the basis of "timeless necessity (demiurge, logos, One)" through the vision of the created world as the will of God and man's life in freedom.

The other two concepts (space and environment), as predominantly geographical determinants, concretize a geographical reality whose specificities have a spatial dimension and we recognize them through regional differences. They were originally derived from physical and environmental characteristics and are a valuable resource for regional geography, which, creates a kind of "historical record of social and natural differences" [2]. They are closely related to concepts: place, region, natural environment and landscape, often defined by dry spatial descriptions, and best understood as ecological entities that have transformed social activities throughout history. That is why it is important to point out immediately the importance of the first term (space) through which the epistemological basis of geography breaks. Geographic knowledge has always been based on the knowledge of space and its cartographic representation. The extension of this knowledge depended on the applicability of various innovations, which led to the creation of new conceptions of space. During the historical development of geography, the notion of space has been modified by specific links between "power, knowledge and geography". During $19^{\text {th }}$ century there was a time when "time" dominated, while $20^{\text {th }}$ century marked "space," during which has gone from modern to postmodern. This was referred to as a "spatial turn" in a wide range of humanities and social sciences, with "conceptualization of space" representing a watershed and between geographical directions [7].

Table 1. Conceptualization of space and development of scientific geography

\begin{tabular}{llllll}
\hline \multicolumn{2}{c}{ Space } & \multicolumn{3}{c}{ Scientific Geography } \\
\hline Concept & Feature & Beginners & Access & Method & Direction \\
\hline \multirow{2}{*}{ Absolute } & Physical & Kant, Humboldt, & Spatial & Classical & Modern \\
& Space & Hettner, Hartshorne & differential. & deduction & geography \\
\hline \multirow{2}{*}{ Relative } & Mathematical & Schaeffer, Bunge, & Quant. & Mathematical & New \\
& Space & Neef, Ullman & revolution & and statistical & geography \\
\hline \multirow{2}{*}{ Relational } & Space & Harvey, Lefevebr, & Social & Historical & Postmodern \\
& Production & Dear, Soja & Practice & Materialism & Geography \\
\hline
\end{tabular}

Contribution to the scientific founding of modern geography was marked by the "concept of absolute space", which developed along the historical vertical that traced Kant with the definition of space within his first critique (Critique of Pure Mind, 1781) and what the Kantian view of space entailed (Kantianism). Humboldt and Hettner expanded the theoretical conception of space, and therefore of modern geography, and gave it its final form to Hartshorne (1939) by introducing the notion of "spatial differentiation" in his capital work "The Nature of Geography." It is precisely the concept of space and its philosophical interpretation that will be the basis for the development of different geographical views of reality in the second half of $20^{\text {th }}$ century, when two more changes 
occurred in the conception of space, which also represented the dividing lines within geography itself. Schaeffer (1959) began the quantitative revolution in geography (the concept of relative space), as the theoretical basis of New geography. To clarify the new concept of space, a more complex geometry was required, which introduced into the spatial analysis (basic method) the process of abstraction, as a prerequisite for the transition from "physical" to "mathematical" space. During this phase in the development of scientific geography, "the antagonistic relationship between space and regional tradition will emerge, when space is artificially isolated from the natural environment" [17]. It resulted in a kind of crisis of the identity of geography and as a consequence of its complexity (natural and social science). The quantification of geographical phenomena and processes was an expression of the need to simplify the meaning and practical needs of geography, which began to lose its academic importance and disappear as a permanent course in reputed universities.

It was similar to the relation between the terms space and place in the 1970 s or, to a lesser extent, space and the natural environment in the 1970s and 1980s. Finally, Lefebvre (1969) introduces the concept of "Production of Space", and Harvey (1973) introduces social practice in geographical research and instead of "What is space?", the question "How is it that different human being's practices create and use characteristic conceptualizations of space?" [17]. This introduced into geography relationally a concept in which space is folded into social relations through practical activities. This is allowed not only for the "socialization of spatial analysis", but also crucial for the "specialization of social analysis", thereby stepping into the world of postmodern geographies. The original and highly influential elaboration of the space-knowledge relationship was offered by Michel Foucault through one of the most comprehensive responses (poststructuralism). Through numerous spatial metaphors, he emphasized the specialization, i.e. the spatial dimension (situationally and locality), which has significantly contributed to the "reaffirmation of space" or "spatial reversal" in the social sciences. According that, knowledge is spatially educated and "only specialized knowledge can have the power of legitimacy, use, practice, and that spaces are created by power / knowledge and discourses" [11].

The term environment indicates the interaction of man with the natural and social environment and expresses a conceptual closeness to the terms landscape and natural environment, reflecting on these issues the intersection of geographical and philosophical. Since these ecological units are characterized by uniqueness and unrepeatability, they are special and different, but their locality should not be romanticized. These differences can be interesting and life-threatening as well. This implies one of the tasks of geography, that it should enable people to understand these similarities and differences and to view them with respect, not in a destructive way. Did we understand this through the postmodern historical and geopolitical messages?

The importance and closeness of these scientific views to the development of nature and human society have led to the search for closer connections between these scientific disciplines, more specifically, the influence of certain philosophical ideas on the development of geographical thinking. Clearly, the development of these scientific ideas has been going on for two and a half millennia continuously, but that does not mean that these sciences during this period, especially geography, existed as independent disciplines in their present form. Its structuring and modern methodological - epistemological concept began to be built on the basis of the adoption of new philosophical opinions and scientific knowledge. Also, this interaction of geography with philosophy created 
situations in which geography became the subject of philosophical research, as it was during the development of German idealism.

"For example, we can think of Kant's Physische Geographie or Hegel's Vorlesungen über die Philosophie der Weltgeschichte (Lectures on Philosophy of World History) as the most significant examples of philosophical interest in geography. However, despite these fundamental links between these scientific opinions, the historical relationships between these disciplines remain unexplored. Certainly, the blame for this lack of research on the history of ideas is equally shared: on the one hand, it is the isolation of geographers; on the other, the disinterest of philosophers" [15].

Therefore, it is very important to review the historical development of major philosophical ideas, which have essentially determined the directions of development of contemporary geography. The beginning of this review, no matter how far and farreaching the subject of this research may be, should begin with ancient philosophy, as the framework from which geography originated. This is important also because of the continuity of certain philosophical ideas, which have been modified over time, persist to this day, and have significantly shaped the structure of geographical thinking. In order to gain a better understanding of the geography of the period, it is necessary to learn the basic epistemological determinants of philosophy. This requires extra effort on the part of the geographer, undoubtedly an effort worth making.

The various bases of abstraction through which the abstraction through which the geographical concepts and processes are generalized are a good basis for understanding the complexity and necessary generalization of geographical concepts and processes emphasizes the possibility of multiple levels of generalization, from metaphilosophy, philosophy, social theory to practice. This can be explained by the fact that two people, thanks to a different level of abstraction, can see a different general structure based on the same set of facts. The notion of metaphilosophy is interpreted as "the existence of the most general perspectives that direct thinking towards culture", that is, it is the link between thinking organized around "theoretical issues on the broadest scale (world views) and cultures" [17]. Metaphilosophy is a channel that conveys cultural values in theoretical terms, but is also active in building theoretical and philosophical beliefs and reflections on culture. It expresses the general purpose of reasoning at the purpose level what people seek in thinking, what they want to justify, the standards, truths, or efficiencies applied to thinking.

In terms of the historical development of philosophy, there is no identical boundary in Anglo-Saxon and continental interpretation of these processes and the boundary between premodern and modern is the end of classical German idealism, which is 1831 (the death of Hegel) $[17,20]$. If Hegel was the "boundary" between premodern and modern, Martin Heidegger (1889-1976) is considered to be that link or divider between modern and postmodern. In the world of geography, the transition to the era of modernity is linked to Humboldt and Ritter (1859), and the entry into the world of the postmodern was in the second half of $20^{\text {th }}$ century, which characterized the emergence of neoliberal capitalism $(1980 \mathrm{~s})$ ?

\section{CHRESTOMATHY}

Consideration of such a complex process as the development of geographical thinking during premodern, in addition to clues about the main ideas and their protagonists, should 
include the selection of works i.e. a chrestomathy ${ }^{19}$ that would indicate the closeness of philosophical ideas and geographical thinking. We believe that an adequate selection of thirteen authors who belonged to different historical periods: ancient, middle ages and modern $(6+3+4)$. In doing so, no proportion was established between the length of a given period and the number of philosophers / geographers to be represented. The ancient period lasted for millennia, and we suggest six of the most significant philosophers who have contributed to the development of geographical thinking in this period. The development of the materialistic worldview, beginning with the School of Miletus through to the Epicurus Academy, is most clearly illuminated by Heraclitus and Lucretius. The first, through cosmological and cosmogonic performances, indicated the importance of eternal movement and fire. Through logos, he also introduced "dialectical" elements, which can be reminiscent of Hegel and Marx, which is that history is triggered by the shifting of opposites. Another wrote a work that represents the origin of learning about the materialistic world (materialism) and sings:

"I will begin the assembly of the essence of the heavens and the Gods, and discover the holy foundations, the first from which nature creates, and nourish, and multiply things, where it is again dissolved when it is destroyed. We call them matter and the birth bodies, the seeds of all things, exposing the significance of theirs, and the basic bodies, because everything comes from them" [10].

The other two philosophers would be Plato and Aristotle, who made a huge contribution to the development of an idealistic world view (idealism), also called an anthropological school. Because of their fundamental contribution to the understanding of society and social processes, and thus the foundations of socio-geographical development, they would give an insight into selected chapters that also point to this geographical aspect. Certainly, these are segments of Plato's "State" and Aristotle's "Politics." Finally, the review of ancient philosophy would end with Strabo and Ptolemy, the founders of geographical thinking. The first in the field of chronographic research and realization of the first comprehensive geographical synthesis of the known world through seventeen books of "Geography". This work represented, in antiquity, the first "real contact between the sublime successes of philosophy with geography" in which fragments of the lost works of Eratosthenes, Hipparchus and Poseidon are preserved. Ptolemy, on the other hand, pursued a number of illustrious scientists (Eratosthenes and Hipparchus) who, through mathematics, "made" geographic representations of the Earth and gave it a scientific character (mathematical geography). In this way, he left the Earth's surface and made his way across the Tetrabiblos into the space of the universe, which, after only one and a half millennia, would be put "on its feet" by the Copernican Craft.

The second major historical period lasted for one millennium and represents the link between the world of antiquity and the world of the Renaissance. It was the Middle Ages, which we present in the "three by three" way. They are three philosophers / geographers, representing three different cultural-civilizational circles that intersect at three points. The first philosopher is al-Mukadasi, who lived in the Holy Land and is one of the first public

\footnotetext{
19 The term chrestomathy is derived from two Greek terms: chrēstós, meaning valid, useful, usable, and máthēsis, meaning learning, science, or knowledge. In accordance with our language, chrestomathy would mean studying what is most valuable to know. In the figurative sense, it refers to the choice of exemplary, instructive places from various writers, more specifically their famous works, somewhat like a role model reader.
} 
workers to declare himself Palestinian. As a member of the minority (Muslim) community among Jews, he made a significant geographical synthesis of the area. The other is Maimonides, a Jewish theologian, physician and travel writer born in Cordoba, but has lived in several cities throughout the majority of the Arab region from the Maghreb to Syria. There was also a convert, but essentially through "taqiya", it proved the possibility of survival, under extreme conditions, within the radical Muslim communities of the time. His work exemplified the limitless willingness to sacrifice in the name of preserving the traces of ethnic and cultural diversity, i.e. the existence of Jews in the area from Yemen to the Maghreb. The third person was a visionary geographer, the guiding star of Portugal and the entire Roman Catholic world in his day. Henrique the Navigator achieved the visions of the European bourgeoisie for the easy acquisition of greater material wealth, but this will only become a short-lived and transient consequence of the expansion of the geographical horizon. On the one hand, the positive aspects of this deepening of geographical knowledge have led, through trade, to the spread of cultural influences and the advancement of material culture throughout the New World. Also, as a markedly negative effect of this spread, there was a half-millennium colonial exploitation of these areas. The most visible consequences of this process were described and noted that the establishment of a slave system (1500-1800) and the forcible transfer of "between 11.4 and 12.5 million African inhabitants to Western Europe and the USA" [5, 1]. The consequences of this vandal act are still visible today, and the focus of the research should be on the scientific and technical solutions in the field of navigation that have made it possible. innovation of navigation devices, production of maps of newly discovered areas and modernization of ships. Most of these assumptions, including the Sagres Naval Training College (Algarve) in Portugal, have been created by Henrique the Navigator as a prerequisite for successful research ventures.

The modern period lasted relatively briefly compared to previous epochs. Between the discovery of America and the year of the death of the two first scientific geographers, Alexander von Humboldt and Karl von Ritter, only three and a half centuries had elapsed, and nothing was the same in the world of science as in geographical thinking. The shackles of ecclesiastical dogma and scholasticism, based on Ptolemaic geography and Aristotelian philosophy, were taken down by the grandiose Nikola Copernicus and with his teachings on the heliocentric system opened the way to other greats of world science, most notably Isaac Newton Galileo Galilee. These greats in the fields of astronomy and physics opened up a whole new space, not only in the natural sciences, so that scientific thinking soon spilled over the dogmatic forbidden borders. Very quickly, tremendous scientific results were also achieved in the field of social sciences, and works of unswerving value were written by, among others, Rousseau and Kant.

\section{CONCLUSION}

Lastly, the content of geographical synthesis should be formulated with the ambition to realize three additional goals. First, it is an attempt to describe a person's fascination with new knowledge, which forced him to explore the earthly that is "beyond his horizon." In this way, man discovered "new worlds", which have a formal origin in the ancient period, and are still current today. For this reason, we can call them philosophical vocabulary the search for the idea of the world. Also, because of the constant questioning about the way of becoming of the world and its structure, man looked up to the sky, yearning for knowledge and seeking an answer, and wondered: "How did it all begin"? By cosmogony, this goal can be defined as the idea of God. Finally, it is the desire to show the 
development of geographical thinking in its long journey of development and to see, in its fullness, its intertwining with other natural and social sciences. Also, the division of geography into two separate parts (natural and social), constantly reminds us that we should search for the idea of man, because during this period we were the same guiding star - philosophy.

\section{REFERENCES}

[1] Angeles, L. On the causes of the African slave trade. Kyklos, UK, vol. 66 (1), 2013, pp 1-33;

[2] Claval, P. An Introduction to Regional Geography, UK, 1998.

[3] Deleuze, G. \& Guattari, F. What is philosophy? US, 1994.

[4] Elden, S. \& Mendieta, E. Reading Kant's Geography, US, 2011.

[5] Eltis, D. et al. The Trans-Atlantic Slave Trade, US, 1999.

[6] Grčić, M. A theoretical concept for the study of civilizations as socio-geographical systems. Demografija, RS, vol. VI, 2009, pp 7-32.

[7] Gregory, D. et.al. The Dictionary of Human Geography, UK, 2009.

[8] Cacciari, M. Geophilosophy of Europe, RS, 2010.

[9] Kremer, H. Criticism of Hermeneutics - Philosophy of Interpretation and Realism, 2010.

[10] Lucretius. De rerum natura, RS, 1951.

[11] Marinković, D. \& Ristić D. Insights from Geoepistemology: Space-Practices-Power, RS, 2016.

[12] Mutabdžija, G. Regional Geography of Europe. US, 2018.

[13] Nietzsche, F. The Down of Day. US, 1911.

[14] Negerestani, N. Cyclonopedia: Complicity with anonymous materials, AUS, 2008.

[15] Papa, E. C. S. Introduction: Philosophy and Geography. Journal of Interdisciplinary history of ideas, vol. 6 (12). 2017, pp 1-9;

[16] Parikka, J. A geology of media. Minneapolis, US, 2015.

[17] Peet, R. Modern geographical thought, UK, 1998.

[18] Resta, K. Geophilosophy of the Mediterranean, RS, 2017.

[19] Rousell, D., Cutter-Mackenzie, A. \& Foster, J. Children of an Earth to Come: Speculative fiction, geophilosophy and climate change education research. Educational Studies, Vol. 53 (6), 2017, pp 654 669;

[20] Unwin, T. The Place of Geography. UK, 1992. 